\title{
Museus de História Natural, Dispositivos Curatoriais e Informação: diafanizações de uma "ordem natural".
}

\author{
Sabrina Damasceno Silva ${ }^{I}$ \\ https://orcid.org/0000-0001-9560-1404 \\ José Mauro Matheus Loureiro ${ }^{\text {II }}$ \\ ${ }^{I}$ Universidade Federal do Recôncavo da Bahia, Cachoeira, BA, Brasil. \\ Docente do curso de Museologia. \\ II Universidade Federal do Estado do Rio de Janeiro, Rio de Janeiro, RJ , Brasil. \\ Docente na UNIRIO e do Programa de Pós-Graduação em Ciência da Informação \\ da Universidade Federal da Paraíba.
}

http://dx.doi.org/10.1590/1981-5344/3147

Ao abordar singularidades nas narrativas sobre as ordenações do "mundo natural", desenvolvidas nos espaços de informação e memória museológicos, considera-se que os processos curatoriais envolvidos são elementos teóricos e práticos integrantes de "dispositivo", conforme a concepção de Michel Foucault. Nesse contexto, a curadoria passa a ser analisada como se fossem irrupções discursivas na "construção de verdades" e sua naturalização pragmática seja quanto à informação, seja quanto ao processo de comunicação social da ciência.

Palavras chave: Museu de História Natural; Dispositivo Curatorial; Informação.

This research approaches the singularities that integrate the narratives constructions on the ordinances of "natural world" undertaken in information and memory museological spaces. The curatorial process evolved are understood as theoretical and practical elements that are 
integral parts of a "dispositive", as developed in the theoretical framework of Michel Foucault. This study analyzed the curatorship as discursive irruption applied to the issue of the "truths" and naturalization of information process in social science communication.

\section{Key-words: Natural History Museum; Curatorial Dispositives; Information.}

Recebido em 19.09.2016 Aceito em 30.07.2019

\section{Introdução}

Os museus de história natural apresentam as interpretações da ciência moderna sobre a natureza e os artefatos dos diversos grupos humanos. Para isso emprega saberes e estratégias formuladas pelo curador (o especialista) destinados à comunicação com o público em geral. Nas análises desse processo, o conceito de "dispositivo", formulado por Michel Foucault (1979, p. 182), permite perceber o que pode ser dito e enunciado nas exposições museológicas, principal veículo de comunicação com o público.

A cada intervenção curatorial ocorre uma disrupção nos processos informacionais consolidados, o que gera diferentes quadros de saber/poder. Subjacente a tais processos encontram-se construções heterogêneas de significados e diferentes acionamentos de sentidos, sobretudo, nos ambientes expositivos museológicos.

Os desafios e questões curatoriais na atualidade prendem-se, sobremodo, à elaboração, recodificação e publicização do conhecimento científico em contextos diferenciados. Se anteriormente o curador "[...] permanecia um resignado supremo, agora precisa encantar o visitante" (HUDSON, 1988, vii). Permanece, contudo, sua função de relacionar os objetos musealizados com os demais itens das coleções e conjunturas sócio-históricas.

Nesse quadro, as pragmáticas ordenadoras da informação empregadas sobre esses conjuntos de objetos a fim de instituir suas fronteiras, possibilidades e interfaces são muitas vezes comprometidas no instante mesmo da coleta, em sua origem e, posteriormente, em sua inserção no interior das coleções. As sistematizações empregadas restringem ainda os múltiplos planos de representação relativos às linhagens, sequências e temporalidades construídas a partir dos valores e classificações estruturadas na racionalidade moderna.

O conceito de curadoria possui significados variáveis em diferentes áreas do conhecimento e espaços de preservação da memória. Há, contudo, um ponto de convergência, especificamente nas instituições museológicas, que se encontraria presente em meio a essa diversidade: 0 especialista. Este seria o sujeito acionador dos "dispositivos enunciativos" que irrompem no campo ao inserir e compor os "discursos" autorizados, 
na medida em que cada concepção curatorial estabelece para os acervos e ações institucionais critérios de "verdade", gestão e comunicação dos bens materiais e simbólicos.

Para refletir sobre os fluxos informacionais presentes no cotidiano desses museus de história natural optou-se então pelo conceito foucaultiano de "dispositivo", formado por uma rede de relações que podem ser estabelecidas entre elementos heterogêneos: discursos, instituições, arquitetura, regimentos, leis, medidas administrativas, enunciados científicos, proposições filosóficas, morais, filantrópicas, o dito e o não dito.

Os aspectos relacionados aos fluxos informacionais no âmbito dos museus são aqui considerados ciclos que se estendem de sua emersão até sua organização e uso, de tal modo que o processo informacional pode ser gerido direta ou indiretamente em diferentes fases de seu curso. Já no que tange à gestão, não denota necessariamente um estado de controle absoluto, mas a capacidade de direcionar, guiar e antecipar sinergias e dissonâncias nas interações entre humanos e a informação (HUVILA, 2013, p. 11).

As atividades voltadas para organizar a informação constituem-se fundamentalmente em sequências ordenadas de interações informacionais com propósitos específicos, relacionadas com a vida cotidiana ou unicamente com a vida profissional do sujeito. Há que se considerar que tais interações não obedecem necessariamente a uma sequência rígida amparada no trinômio produção, aquisição e uso, mas revestem-se de complexidades, ambiguidades, volatilidades, situacionalidades e interações intersubjetivas.

Assim sendo, a gestão dos processos informacionais torna-se mais difícil, mas necessária no que tange às suas formas de validação (HUVILA, 2006, p. 2). As diferentes relações de saber/poder presentes nos espaços de informação e memória ensejam a percepção da naturalização da questão informacional nas rotinas de trabalho e nos processos de transmissão e reprodução efetuadas a partir de documentos e coleções dos museus (HUVILA, 2013, p. 11).

Uma das técnicas utilizadas na preparação do acervo de história natural é empregada como metáfora para representar as elaborações expositivas museológicas dessas instituições: a "diafanização", que consiste no uso de substâncias químicas para tornar transparentes os tecidos moles de diferentes espécimes, de forma a permitir o estudo detalhado das suas estruturas ósseas.

A análise que se propõe, do mesmo modo, permitiria perceber a organização e estratégias de uso da informação contidas nos acervos, bem como as configurações dos processos info-comunicacionais que estruturam as exposições museológicas.

\section{A curadoria como dispositivo}

Os "gabinetes de curiosidades", surgidos nos séculos XVI e XVII na Europa Ocidental, constituíam-se em espaços destinados a reunir espécimes naturais, objetos de química, artes, dentre outros. Desse 
modo, buscavam uma representação da totalidade por meio da materialidade ali depositada.

Nesses ambientes encontravam-se, simultaneamente, a gênese dos museus de história natural e da figura do curador, isto é: daqueles responsáveis por "proceder à cura" dos diferentes objetos que compunham as coleções; e tais configurações delinearam uma das principais características dos espaços museológicos dedicados à história natural: a busca por construir um microcosmo representativo do mundo (LEOPOLD, 1995, p. 151-157).

Posteriormente, no século XIX, estas instituições museológicas adotaram uma configuração baseada nas especializações e fragmentações das coleções por tipos de objetos. Tal mudança deveu-se à prevalência das novas ordenações disciplinares ocorridas no campo científico. Os curadores, então responsáveis pela pesquisa, formação de coleções e fluxo da informação, privilegiavam a comunicação intrapares.

À época dois elementos imprimiram características que marcam essas instituições até à atualidade: o aprofundamento das divisões disciplinares que conduzem ao reordenamento espacial dessas instituições e, concomitantemente, a reunião de diferentes temporalidades, o que permitiu às exposições museológicas tornarem-se uma forma de caminhar organizadamente através do tempo evolucionário (BENNET, 1995, p. 96).

No decorrer do século XX, muito embora os espaços museológicos continuassem a possuir laboratórios, a pragmática de pesquisa modificouse gerando um afastamento entre os quadros científicos em desenvolvimento e as exposições apresentadas nos museus de história natural. Em algumas instituições, certas áreas do conhecimento migraram para espaços físicos exteriores aos museus e definiram novos meios de controle e manipulação das coleções.

Esse afastamento causou um declínio desta tipologia de museus em virtude do distanciamento desses profissionas das coleções e dos pesquisadores e na adoção de um viés expositivo baseado na glorificação da ciência moderna, tornando-se monumentos dos sucessos científicos passados (DELICADO, 2009, p. 118). Os curadores, entretanto, permaneceram sendo os pesquisadores e expertises em áreas específicas do conhecimento.

O conceito de "dispositivo", desenvolvido por Foucault (1979), permite analisar o complexo de relações composto por diferentes práticas discursivas e não-discursivas subjacentes às práticas curatoriais, e por extensão, às construções expositivas museológicas. Segundo o autor, o "dispositivo" compõe-se de elementos discursivos e não-discursivos de cunho heterogêneo. (FOUCAULT, 1979, p. 182). No âmbito discursivo se dá a composição do enunciável e do visível, das palavras e das coisas, dos discursos e das arquiteturas, dos programas e das "formações discursivas e não-discursivas". São, portanto, formados por relações que estabelecem, interrelacionam e geram sentidos na sociedade (KLEIN, 2007, p. 215-216). Os "dispositivos", assim caracterizam-se como: 
[...] um conjunto decididamente heterogêneo que engloba discursos, instituições, organizações arquitetônicas, decisões regulamentares, leis, medidas administrativas, enunciados científicos, proposições filosóficas, morais, filantrópicas, em suma: o dito e o não-dito [...]. O dispositivo é a rede que se pode estabelecer entre esses elementos. (FOUCAULT, 1982, p. 89).

Para o desenvolvimento do conceito de "dispositivo", Foucault priorizou três níveis de problematização ${ }^{1}$. O primeiro relacionado à sua constituição: a rede de relações que pode ser estabelecida entre elementos heterogêneos (discursos, instituições, arquitetura, regimentos, leis, medidas administrativas, enunciados científicos, proposições filosóficas, morais, filantrópicas, o dito e o não dito). A seguir, a natureza dessa rede onde busca o vínculo e o nexo que se pode estabelecer entre esses elementos heterogêneos. Por fim, aborda a formação que em um dado momento respondeu a certa urgência conferindo-lhe uma função estratégica. Nesse quadro, destacam-se dois momentos essenciais: o objetivo estratégico e a constituição do dispositivo propriamente dito (Foucault, 1979, p. 181).

O "dispositivo", como uma rede estabelecida entre elementos heterogêneos (GARCÍA FANLO, 2011, p. 1), não é algo abstrato, mas encontra-se situado histórica, espacial e temporalmente; e sua emergência responde sempre a um acontecimento gerador de sua aparição. Para que se torne inteligível é necessário estabelecer suas condições de aparição em um acontecimento que modifica um campo prévio de relações de poder considerando que ele não é externo à sociedade e vice-versa. Da mesma forma deve ser pensada a relação entre os "dispositivos" e os sujeitos (GARCÍA FANLO, 2011, p. 6).

Como possibilidade analítica dos museus de história natural, o conceito de "dispositivo" exige observar a rede ${ }^{2}$ cujas conexões são integradas por práticas discursivas e não-discursivas que reconfiguram sua natureza e associações com outras instituições buscando desvelar as singularidades, uma vez que sua emergência responderia sempre a um acontecimento historicamente particular (GARCÍA FANLO, 2011, p. 6).

Seu emprego permitiria a apreensão das peculiaridades curatoriais, das enunciações científicas presentes nas construções expositivas e da elaboração de produtos de pesquisas científicas no cotidiano institucional. Revelaria ainda, os agenciamentos realizados pelos curadores no que tange aos atravessamentos, às relações de poder, às dinâmicas institucionais específicas e locais que determinam o processo de seleção

${ }^{1}$ Originalmente publicada na revista Ornicar no 10, em 07/77, como: "Le jeu de Michel Foucault". No Brasil foi publicada por Roberto Machado no livro Microfísica do poder citado nas referências com o título: Sobre a história da sexualidade I. Nas respostas Foucault (1982) aborda mais precisamente os três níveis de problematização presentes nos dispositivos

${ }^{2} \mathrm{O}$ termo rede aqui é empregado segundo as conceituações de dispositivo foucaultianas 
de temáticas científicas de exposições, bem como às informações, conceitos e objetos que serão incluídos na narrativa expositiva disponibilizada ao público.

O curador, nas ações referentes à exposição museológica, ocupa um lugar pautado pelas dinâmicas internas institucionais, ou seja, entre o museu, suas atividades e a sociedade. Assim considerado, o conceito de "dispositivo" configura-se um instrumento para o entendimento das intencionalidades, construções e ordenações no interior dessa rede de práticas, permitindo a percepção das singularidades curatoriais nos museus de história natural de forma mais ampla, não apenas no seu aspecto de configuração discursiva, mas em toda uma relação com a estrutura institucional, os regimentos e as singularidades locais de cada museu.

\section{3 "Curatore"/Curador: as pragmáticas curatoriais}

O surgimento da história natural em meio à Modernidade ${ }^{3}$ europeia possui intrínseca relação com o ritmo de mudanças nos modos interpretativos e de instrumentalização da natureza. Os fatos naturais a partir daquele momento são ordenados e interpretados a partir de uma classificação, codificação e sistematização baseada em uma nova hierarquia entre o homem e a natureza. (LOUREIRO, 2007, p. 161).

Desse modo, a História Natural passa a se constituir como uma narrativa humana de transcendência, onde a domesticação de plantas e animais figura como uma contrapartida da própria domesticação da humanidade no processo civilizatório (INGOLD, 2000, p. 77). A consolidação da História Natural acelera a proliferação dos acervos científicos dos museus na Europa a partir de século XVIII. Em um primeiro momento a utilidade desses espaços museológicos reside prioritariamente nas práticas de observação, descrição, sistematização e aplicação de métodos de investigação. (LIMOGES, 1980, p. 211-240).

Desde sua gênese os museus de história natural possuem a difícil tarefa de combinar dimensões oriundas de um projeto de memória da universalidade do saber científico, o que pressupunha uma neutralidade, e, ao mesmo tempo, a promoção particular de identidades nacionais modernas (DUARTE, 2003, p.28). As formas de agenciamento dessas duas dimensões variaram localmente desde o século XVIII, em virtude, tanto da história da razão científica como do ideal nacional.

0 movimento Romântico ${ }^{4}$, no século XIX, enquanto reação à ordem intelectual Iluminista, forneceu elementos para uma reconfiguração dos

${ }^{3}$ A modernidade se caracteriza, portanto, pela supremacia do ser enquanto pensador e enquanto dominador do mundo pela razão". A questão da neutralidade no pensamento deve passar por uma experimentação metodológica orientada e, é o mito dos modernos (FRANCELIN, 2004, p. 51).

4 "(...) o romantismo sempre será o contraponto, o momento segundo, de uma dinâmica que o ultrapassa e determina. Ele encarna, nos termos do modelo de Louis Dumont, a dimensão 
museus que caracterizam muitas de suas feições até os dias atuais. Para tanto, contribuiu o conceito de "totalidade", um dos pilares românticos inscritos na Naturphilosophie, entendido como a mais abrangente de suas dimensões constitutivas.

Essa perspectiva gerou uma nova apreensão dos fenômenos sociais e naturais ao possibilitar por meio de novas visadas científicas a apreensão dos seres vivos como uma totalidade em si, de um ponto de vista orgânico em contraposição à hegemonia mecanicista (LOUREIRO, 2007, 162). Simultaneamente, a história natural generalista deu lugar à fragmentação e consequentemente á especialização disciplinar (Botânica, Geologia, Zoologia, Antropologia) e suas subdivisões (Mastozoologia, Herpetologia, Ornitologia, Malacologia). Os museus de história natural contribuíram para suprir a primeira condição institucional para a emergência desses novos saberes. (BENNET, 1995, p. 96).

No caso brasileiro, destacam-se duas dimensões desses espaços museológicos: sua capacidade de elaboração discursiva acerca da universalidade científica e, concomitantemente, os valores da particularidade nacional, constituindo uma espécie de "[...] legitimação universalista do particularismo [...]" (DUARTE, 2003, p. 7). Coletar, pesquisar e expor, são os três atributos tradicionais que identificam os museus de história natural. No presente, contudo, reconhece-se também a sua contribuição para a preservação da natureza já que suas coleções configuram-se como patrimônio genético de formas de vida em extinção ou modos de analisar as modificações de habitat e das próprias espécies ameaçadas.. Ao longo do tempo, a vinculação dos museus de história natural a disciplinas científicas heterogêneas permitiu que seus acervos abrangessem os elementos referentes à Vida (Bio), ao Cosmos e à Cultura. Essa feição única os singulariza frente às demais tipologias de museus.

Mas independentemente de sua tipologia, museus possuem múltiplas significações construídas por diversos sujeitos com contribuições diferenciadas na construção de significados derivados das diversas interpretações do social. As coleções museológicas, contudo, possuem em comum o fato de serem constituídas por objetos advindos do passado e reunidas intencionalmente por um proprietário ou curador que acreditava que o todo é maior do que a soma das partes. São vistas, assim como "[...] um imenso corpo complexo de evidência material, um arquivo que abrange não só às evidências materiais de nosso passado natural e humano, mas também como este passado tem sido ele mesmo interpretado" (PEARCE, 1993, p. 134).

As pragmáticas curatoriais influenciam enormemente todo esse processo. As origens de suas ações possuem, assim como os museus

hierárquica, holista, do pensamento humano, oposta à ideologia do individualismo. Eis por que se poderia e deveria reconhecer como "romântica" toda contra-força fundamental em nossa dinâmica cultural desde o final do século XVIII (...) (DUARTE, 2004, p. 8). 
modernos, duas linhagens que se entrecruzam em alguns períodos históricos; os acervos oriundos da natureza, por exemplo, demandavam ações de "proceder à cura" de suas coleções, já os acervos artísticos exigiam ações relativas a "proceder à manutenção" de seus acervos de arte.

Essa dualidade de ações gerou uma diversidade de especializações de museus e o surgimento de diferentes categorias profissionais como a do curador e do conservador. "[...] Essa perspectiva consolidou, por exemplo, as diferenças iniciais entre os perfis dos Museus de História Natural em relação aos Museus de Arte, e até o século XIX essa diversidade tipológica caracterizou o universo dos museus [...]" (BRUNO, 2008, p. 27).

[...] "proceder à cura" passou a ser interpretado como um conjunto de procedimentos inerentes à seleção, coleta, registro, análise, organização, guarda e difusão do conhecimento produzido. [...] Nesse sentido, as noções herdadas de "organização e guarda" ampliaram e particularizaram os aspectos constitutivos da definição de curadoria e, ao mesmo tempo, consolidaram diversos campos de conhecimento. Essa definição, gradativamente, passou a ser difundida a partir de publicações de periódicos especializados das mais variadas áreas científicas, [...] mas uma observação pormenorizada dessas instituições nos faz perceber que essa herança chegou ao século XX permeada por ações isoladas, com pouca inspiração democrática e vocacionada ao protagonismo. [...] Essas idiossincrasias, de alguma forma distanciam a definição de curadoria, que é compreendida como o conjunto de atividades solidárias, em relação à definição de curador, quando esse é visto como um profissional onipotente em relação à dinâmica institucional. (BRUNO, 2008, p. 28)

O século XIX é o momento de irrupção dos "discursos" referentes à curadoria em museus, ou seja, relativo aos procedimentos internos que regem o "discurso" e se voltam para a constituição dos "enunciados" acerca de si. Estabelecem, dessa maneira, uma "origem" que justifica a existência de práticas e posições dos sujeitos, legitima relações de saberpoder, estratégias e reificações de "discursos" institucionais.

As informações que determinam as temáticas e os conteúdos dos enunciados nas exposições de história natural possibilitam analisar o aspecto preponderantemente decisório e autoral da curadoria científica na elaboração de narrativas expositivas que se ocultam sob os discursos institucionais. Nessa curadoria o discurso do cientista é determinante quanto àquilo que pode ser dito de verdadeiro (FOUCAULT, 2007, p. 19), ainda que posteriormente venha a ser decodificado ou transposto para 
uma linguagem acessível ao público por meio de exposições (divulgação da ciência).

A representação da ciência nesses ambientes reduz-se a enunciações historicizadas e lineares centradas em figuras do passado e ideais-tipo. Embora possam ser constatados alguns exemplos de imagens de cientistas atuais em atividade, as informações relativas à carreira científica, as formas de recrutamento, formação e controle, o funcionamento de instituições de investigação e a estrutura do sistema científico encontram-se alijadas (VINCK, 1995, p. 42).

\section{Socialização dos saberes científicos: diafanizando a transmissão da informação a partir de curadorias}

Os processos curatoriais nos museus de história natural empreendem uma construção dos "discursos" baseados no pressuposto da ciência moderna e contemporânea como o único saber capaz de interpretar o "real". Os quadros informacionais neste caso balizam a "ordem do discurso", isto é, posições onde os sujeitos lutam pelo poder de proferir "enunciados". Desse modo, o curador determina a ordenação e a produção de enunciados relativos ao acervo, bem como o que pode ser dito, em que circunstâncias e com que objetivo e estratégia, objetivando sua construção como verdade.

Configurações institucionais e relações de poder estabelecidas no universo curatorial ocasionam ocultamentos de enunciados estruturados em modelos advindos dos protocolos do universo científico, impedindo a emersão de discursos heterogêneos. As dinâmicas e transformações dos regimes curatoriais no âmbito da comunicação social da ciência geram "dispositivos" e artefatos informacionais, de maneira geral, vinculados às políticas institucionais produtoras e propagadoras de um saber científico perpetuamente provisório e de valor universal que é parte integrante da história do Ocidente (VEYNE, 2011, p. 155).

Os museus como instâncias de preservação, documentação, representação e comunicação da memória social ensejam o desenvolvimento de estudos relacionados ao fenômeno informação como elemento estruturante dos "discursos" e "enunciados". O caráter dinâmico da informação gera novos "dispositivos" e artefatos advindos das condições e meios de sua produção resultando em expressiva influência sobre as políticas inscritas na produção e comunicação do conhecimento científico.

A questão política, segundo Foucault, não seria o erro, a ilusão, a consciência alienada ou a ideologia, mas a própria verdade, uma vez que ela teria um papel relevante nas sociedades ocidentais, produtoras de um saber científico, perpetuamente provisório e de valor universal (VEYNE, 2011, p. 155).

Os diferenciais pragmáticos da informação, resultantes de diversas gramáticas socioculturais, acabam por se desdobrar em uma diversidade de mediações e linguagens, ainda que cada vez mais sujeitas "[...] a 
janelas tecnológicas que sobrecodificam suas possibilidades e limites de geração e transmissão" (HUVILA, 2006, p. 25).

Todas essas transformações materiais e simbólicas encontram-se inseridas no cenário dos "dispositivos de informação" influenciando, sobremodo, as instituições de memória em seus empreendimentos de publicização dos saberes científicos, o que se realiza a partir dos modelos de comunicação pública da ciência para a sociedade em geral, por meio de um processo no qual o público ocupa o papel de mero receptor. As enunciações elaboradas para este fim por especialistas e curadores nos museus científicos se dão a partir de ordenações e escolhas inscritas nos "jogos de forças" que resultam em construções narrativas sobre algo que já se encontra elaborado nas "formações discursivas".

No âmbito da Ciência da Informação todo esse processo vincula-se à Comunicação Científica que compreende as ações vinculadas à produção, disseminação e uso da informação, desde a concepção que origina a pesquisa científica até sua aprovação como conhecimento científico (GONZÁLEZ DE GÓMEZ, 2000, p. 71). A Comunicação Científica é formada pelas ações de "Disseminação", comunicação intra-pares, "Difusão", comunicação extra-pares e a "Divulgação Científica", focada na decodificação, circulação da informação em ciência e tecnologia para o público em geral (BUENO, 1985, p. 142).

Em última análise, todas essas pragmáticas encontram-se na esfera da transferência da informação entendida aqui como um conjunto de ações sociais com que os grupos e instituições se organizam e implementam a comunicação da informação, através de procedimentos seletivos que regulam sua geração, distribuição e uso (GONZÁLEZ DE GÓMEZ, 1993, p. 217).

Nos museus de história natural a preservação de acervo e exposição efetuada pelos profissionais de museus encontram-se vinculadas a questões relacionadas à informação, política e poder, que se revelam, sobretudo, nas práticas de divulgação científica advindas dessas produções que se encontram conjugadas à apropriação social da informação, do conhecimento e da cultura. As exposições museológicas, integrantes do universo da divulgação científica, consistem em narrativas institucionais que legitimam as elaborações da ciência, não como possibilidade, mas como leitura verdadeira do "real". Os processos curatoriais nesse contexto elaboram as ordenações cientificizadas que estruturam essas narrativas expositivas.

Como forma metafórica da percepção dessas práticas informacionais curatoriais pode-se utilizar uma das práticas cotidianas realizadas nos museus de história natural em diversas coleções preservadas em álcool para estudo anatômico e até mesmo para anatomia humana: a técnica de "diafanização", que consiste em tornar uma amostra tecidual transparente ou translúcida por meio do uso de solventes.

A ideia de tornar translúcido, revelar estruturas por meio de agentes químicos, pode servir metaforicamente para pensar os processos de validação da verdade da ciência por meio dos discursos elaborados nos museus. As práticas e processos que resultarão nas escolhas dos 
curadores nessas instituições também se transformarão e consolidarão com o tempo de acordo com interesses e relações diversas. $E$ o enrijecimento dos tecidos pode ser comparado às dinâmicas internas institucionais onde o curador é a figura preponderante de autoridade, que predomina nas relações de poder internas dos espaços concedidos, para que exerça tal autoridade discursiva nos processos de concepção de narrativas acerca de suas especialidades científicas.

Tais processos explicitados permitem ir mais além do que a ordenação discursiva a partir das regras de formação do discurso. Ao inserir as exposições públicas nos processos de comunicação social da ciência, onde a divulgação científica é um dos meios adotados, a "diafanização" dá transparência a um 'dispositivo" que pode ser percebido em instituições de história natural que possuem por finalidade a publicização da ciência nos heterogêneos "discursos" de seus núcleos de pesquisa, seus regimentos, enunciados científicos - os divulgados e os ocultados - elaborados por seus pesquisadores nos processos curatoriais.

\section{Considerações Gerais}

A curadoria no interior dos museus de história natural constitui-se essencialmente dos processos de seleção, ordenação, gestão e comunicação pública da ciência por meio de seus acervos. Os processos envolvidos estão relacionados com a consolidação da ciência ocidental moderna, suas transformações e especializações.

A especificidade da ciência pauta e baliza a incorporação de conjuntos de objetos materiais aos acervos institucionais a partir de suas potencialidades informativas, em especial sua capacidade enunciativa e estabelecem critérios de organização e salvaguarda. As práticas empregadas no cotidiano das instituições museológicas de história natural geram espaços discursivos de "verdades" a partir de estratégia infocomunicacional de valores oriundos da ciência.

A questão da construção de "verdades" nos espaços museológicos possui múltiplas abordagens, entretanto, opta-se por entender que muitos espaços de história natural ainda guardam em sua essência os princípios dos "gabinetes de curiosidades" que deram origem a esta tipologia de museu. Essas instituições apresentam, em suas exposições os elementos materiais de uma nova cultura ou espécie, como uma nova descoberta do mundo desconhecido e reunidos como exemplares únicos, seguindo o princípio de que os museus ocidentais modernos foram gerados para guardar coleções e apresentar verdades.

No que tange à comunicação social da ciência por meio de exposições, vale ressaltar que o processo de escolha do enunciado, a forma como é apresentado e como o processo de recodificação se elabora, pode tornar-se uma simplificação que comprometa inclusive a veracidade do conteúdo divulgado. Trata-se de disponibilizar uma "verdade simplificada" para que esta se encaixe nas limitações (físicas e conceituais) da exposição ou pressuposições de seus curadores. 
Museus podem apenas estabelecer diálogos com seus públicos onde fique claro uma espécie de acordo no que tange à abstração do formato a ser adotado para as representações de temáticas complexas; entretanto, esses processos não ocorrem em função da visão preponderante do especialista, prevalecer em detrimento das demandas do que a sociedade espera encontrar nos museus quanto às temáticas de determinadas áreas do conhecimento.

O conceito de curadoria possui significados variáveis em diferentes áreas do conhecimento e espaços de preservação da memória. Há, contudo, um ponto de convergência, especificamente nas instituições museológicas, que se encontraria presente em meio a essa diversidade de concepções: a atribuição a uma figura decisória (o especialista). Este pesquisador possuidor de expertise possui poder de ordenação dos "enunciados" oriundos de saberes, práticas específicas e, por conseguinte, das "formações discursivas" que irão compor os "discursos" autorizados. Tal sujeito enunciativo estabelece critérios de "verdade", gestão e comunicação dos bens materiais e simbólicos integrantes de acervos e ações ${ }^{5}$ institucionais.

Nos processos info-comunicacionais presentes nas exposições dos museus de história natural "proceder à cura", diz respeito à imposição de valores, legitimidade e domínio que favorecem aos discursos oficiais que integram formatações institucionais, políticas e científicas que determinam coercitivamente os papéis de narradores e de simples expectadores.

O cotidiano curatorial deve ser percebido a partir de suas irrupções discursivas específicas que conferem legitimidade às formas e conteúdos das produções museológicas. Enquanto práticas ordenadoras dos "discursos", elas excluem as diversas possibilidades enunciativas da diferença, dos questionamentos possíveis, do conflito e da heterogeneidade das próprias práticas do fazer científico e dos saberes como um todo. Acabam, dessa maneira, por corroborar uma visão homogeneizante e voltada para o controle de desvios interpretativos por meio da centralização dos paradigmas.

Ao serem "diafanizados" esses processos de comunicação social dos produtos da pesquisa científica deixam transparecer coerções, acionamentos estratégicos, validações de enunciados científicos que se encontram enrijecidos nessas estruturas por trás dos tecidos tornados translúcidos. O acionamento de enunciados de determinadas relações de saber-poder. A informação sob a rubrica institucional acompanha uma série de aspectos da relação saber-poder e a divulgação científica como categoria de construção de discursos, ao produzir informações balizadas nos saberes da ciência, trabalharia domínios de interesses de poder.

A singularidade dos museus de história natural se encontra justamente nesta busca heterotópica de justaposição de ordenação de

${ }^{5}$ Essas ações são relativas à seleção, preservação - desde a conservação física, bem como a parte informacional acerca do objeto - documentação e inserção nas "formações discursivas" expositivas. 
objetos de tempos e origens diversas em espaços definidos, um tour de force para eliminar as dispersões e estabelecer formações discursivas. Faz-se necessário, deste modo, desnaturalizar as práticas cotidianas referentes à informação e aos processos curatoriais complexos e permeados por atravessamentos de diversas ordens.

\section{Referências}

BENNET, Tony. The birth of the museum: history and theory. London: Routledge, 1995;

BRUNO, Cristina. Os caminhos do enquadramento, tratamento e extroversão do patrimônio cultural. In: JULIÃO, Letícia; BITTENCOURT, José Neves (Coord.) Cadernos de Diretrizes Museológicas 2: mediação em museus:curadorias, exposições, ação educativa. Belo Horizonte:

Secretaria de Estado de Cultura de Minas Gerais, 2008. p. 22-34

BUENO, Wilson da Costa. Jornalismo científico: conceitos e funções.

Ciência e Cultura, n. 37. v. 9, p.1420-1421, 1985.

DELICADO, Ana. A musealização da ciência em Portugal. Lisboa: Fundação Calouste Gulbekian, 2009.

DUARTE, Luiz Fernando Dias. La nature nationale: entre I'universalité de la science et la particularité symbolique des nations. Civilisations, Bruxelas, v.52, n. 2, p. 7-33, 2003. (Museums, Collections, Interpretations - Rethinking the construction of meanings and identities).

FOUCAULT, Michel. Microfísica do poder. Rio de Janeiro: Graal, 1979.

FOUCAULT, Michel. A História da sexualidade $I$ : a vontade de saber. Tradução de Maria Thereza da Costa Albuquerque e J. A. Guilhon de Albuquerque. Rio de Janeiro: Graal, 1982.

FOUCAULT, Michel. As palavras e as coisas. 8.ed. Tradução Salma T. Muchail. São Paulo: Martins Fontes, 1999.

FOUCAULT, Michel. A Arqueologia do saber. 7.ed. Tradução Luiz F. B. Neves. Rio de Janeiro: Forense Universitária, 2007.

FRANCELIN, Marivalde Moacir. Configuração epistemológica da Ciência da Informação no Brasil em uma perspectiva pós-moderna: análise de periódicos da área. Ciência da Informação, Brasília, DF, v. 33, n. 2, p. 4966, maio/ago. 2004.

GARCÍA FANLO, Luis. ¿ Qué es um dispositivo?: Foucault, Deleuze, Agamben. A Parte Rei 74, Revista de Filosofia, mar. p. 1-7, 2011.

GONZÁLEZ DE GOMEZ, Maria Nélida. A representação do conhecimento e o conhecimento da representação: algumas questões epistemológicas. 
Ciência da Informação, Brasília, DF, v. 22, n. 3, p. 217-222, set./dez., 1993.

GONZÁLEZ DE GOMEZ, Maria Nélida. O caráter seletivo das ações de informação. Informare, Rio de Janeiro, v.5, n. 2, p. 7-31, 2000.

HUDSON, Keneeth. Museums of Influence. Cambridge: Cambridge Press, 1988.

HUVILA, Isto. To whom it may concern? The users and uses of digital archaeological information. In: INTERNATIONAL CONFERENCE ON COMPUTER APPLICATIONS AND QUANTITATIVE METHODS IN ARCHAEOLOGY (CAA), 35., 2007. Berlin. Proceedings [...] Berlin, 2006.

HUVILA, Isto. How a museum knows? structures, work rules, and infratestructures of information work. Journal of the American Society for Information Science and Technology (JASIST), p. 11-14, June 2013.

INGOLD, Tim. The perception of the environment. London: Routledge, 2000.

LIMOGES, C. The development of the museum d'HistoireNaturelle of Paris 1800-1914. In: FOX, Robert; WEIZ, George. The organization of Science and Technology in France 1808-1914. Cambridge: Cambridge University, 1980. p. 211-240.

LOUREIRO, José Mauro M. Entre "natureza morta" e cultura viva: os museus de história natural. Revista da Sociedade Brasileira de História da Ciência, Rio de Janeiro, v. 5, n. 2, p.161-171, 2007.

PEARCE, Susan. Museums, objects and collections. Washington:

Smithsoniam Institution ,1993.

VEYNE, Paul. Foucault: seu pensamento, sua pessoa. Rio de Janeiro: Civilização Brasileira, 2011.

VINCK, Dominic, Sociologie des sciences. Paris: Armand Colin. 1995. 